\title{
THE
}

\section{The challenges of using polyethylene passive samplers to determine dissolved concentrations of parent and alkylated PAHs under cold and saline conditions}

\author{
Pamela J. Reitsma \\ University of Rhode Island \\ Dave Adelman \\ University of Rhode Island, dadelman@uri.edu \\ Rainer Lohmann \\ University of Rhode Island, rlohmann@uri.edu
}

Follow this and additional works at: https://digitalcommons.uri.edu/gsofacpubs

\section{The University of Rhode Island Faculty have made this article openly available. \\ Please let us know how Open Access to this research benefits you.}

This is a pre-publication author manuscript of the final, published article.

Terms of Use

This article is made available under the terms and conditions applicable towards Open Access

Policy Articles, as set forth in our Terms of Use.

\section{Citation/Publisher Attribution}

Reitsma, P., Adelman, D., \& Lohmann, R. (2013). The challenges of using polyethylene passive samplers to determine dissolved concentrations of parent and alkylated PAHs under cold and saline conditions.

Environmental Science and Technology 47(18), pp 10429-10437.

Available at: http://dx.doi.org/10.1021/es402528q

This Article is brought to you for free and open access by the Graduate School of Oceanography at DigitalCommons@URI. It has been accepted for inclusion in Graduate School of Oceanography Faculty Publications by an authorized administrator of DigitalCommons@URI. For more information, please contact digitalcommons-group@uri.edu. 


\section{The challenges of using polyethylene passive samplers to determine dissolved concentrations of parent and alkylated PAHs under cold and saline conditions}

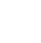

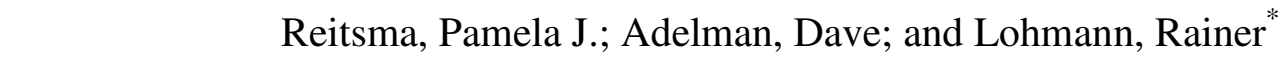

Graduate School of Oceanography, University of Rhode Island, Narragansett, Rhode Island 02882-1197, USA

* corresponding author: Tel: 001-401-874-6612, Fax: 001-401-874-6811,E-mail:

lohmann@gso.uri.edu

\section{Abstract}

Passive samplers can be useful tools to determine truly dissolved concentrations of organic contaminants in the water. Polyethylene (PE) samplers were validated for measuring polycyclic aromatic hydrocarbons (PAHs), with a focus on alkylated PAHs that can dominate in an oil spill. Equilibrium partition coefficients $\left(K_{\mathrm{PEw}}\right)$ between water and PE passive samplers were measured for 41 PAHs both at ambient conditions $\left(20{ }^{\circ} \mathrm{C}\right.$, no salt), down to $-15^{\circ} \mathrm{C}$ and 245 psu present in ice brine. For each additional alkylated carbon, $\log K_{\text {PEw }}$ increased by an average of $0.40( \pm 0.20)$ $\log$ units, close to predictions. The increase per aromatic carbon was only $0.33( \pm 0.02) \log$ units. Apparent PE-water distributions of pyrene and deuterated pyrene (performance reference compound) were within $0.1 \log$ unit for all experiments at 20 and $2{ }^{\circ} \mathrm{C}$, but started to diverge by $0.8 \log$ units $\left(-4^{\circ} \mathrm{C}, 100 \mathrm{psu}\right)$ and $3.1 \log$ units $\left(-15^{\circ} \mathrm{C}, 245 \mathrm{psu}\right)$. The delay in equilibrating PAHs in these experiments was dominated by increases in the water's viscosity, which in turn affected both the PAHs' aqueous diffusivity and the thickness of the water boundary layer. In a 
23 simulated marine oil spill in the laboratory, PE-based results were within a factor of 2 for the

24 most abundant PAHs compared to conventional sampling results.

\section{INTRODUCTION}

The dangers of drilling for oil in the marine environment were recently realized in April

282010 when 4.9 billion barrels of oil were released into the Gulf of Mexico. Over a year later, it

29 is thought the majority of the oil has been cleaned up or degraded by bacteria that inhabit the

30 warm waters of the Gulf of Mexico. ${ }^{1,2}$ In contrast, the Exxon Valdez oil spill occurred in 1989,

31 releasing over 11 million gallons of crude oil onto the shores of the Alaskan coastline. It is

32 estimated that 21,000 gallons of oil still persist today, over twenty years after the spill occurred,

33 with contested remaining toxicity. ${ }^{3,4}$ The Arctic is a unique environment and it is still not

34 understood how spilled oil behaves there. As interest in expanding vessel traffic, as well as the

35 exploration of oil and gas reserves in the Arctic increases, so does the need to better understand

36 the impact of oil spills to this unique environment. ${ }^{5}$

37 Passive samplers have been proven to accumulate compounds, such as polycyclic

38 aromatic hydrocarbons (PAHs), in proportion to the truly dissolved concentration of the

39 compound present in the aquatic environment. ${ }^{6-8}$ In fact, passive samplers actually directly

40 reflect the compounds' chemical activity (which is routinely approximated by its truly dissolved

41 concentration). This can be used, among others, to elegantly measure gradients in the

42 environment, or contribution to mixture toxicity. ${ }^{8-10}$

43 Equilibrium partition coefficients between polyethylene $(\mathrm{PE})$ and water $\left(K_{\mathrm{PEw}}\right)$ are

44 generally determined in the laboratory under standard conditions ( $298 \mathrm{~K}$, no salt) and are used to 
45 relate the passive sampler concentration $\left(\mathrm{C}_{\mathrm{PE}}\right)$ to the dissolved concentration in the water column

$46\left(\mathrm{C}_{\mathrm{W}}\right.$; equation 1$)$ :

$$
K_{P E w}=\frac{C_{P E}}{C_{w}}
$$

$48 K_{\text {PEw }}$ is the ratio of the concentration of the compound in the passive sampler (e.g., ng/ $\left.\mu \mathrm{L}\right)$ over

49 the concentration of the compound in the water (e.g., $\mathrm{ng} / \mu \mathrm{L})$ under standard conditions.

50 Once the $K_{\mathrm{PEw}}$ is known for a compound and a PE is equilibrated in the environment (or

51 corrected for non-equilibrium), the concentration of the compound in water (i.e., truly dissolved)

52 can then be calculated from equation (1). $K_{\mathrm{PEw}}$ can be corrected for a temperature other than 298

$53 K$ by using the van't Hoff equation. To account for the effects of dissolved salts on $K_{\mathrm{PEw}}$, the

54 empirical Setschenow constant $\left(K_{\mathrm{S}}\right)$ and the molar concentration of salt [salinity], present in the

55 water, are used. Both of these equations have been proven reliable at moderate temperatures

$56 \quad\left(30^{\circ} \mathrm{C} \text { to } 2^{\circ} \mathrm{C}\right)^{6}$ and salinities $(0 \text { to } 36.7 \mathrm{psu})^{11}$.

57 Passive samplers are a useful alternative to conventional direct measurement of

58 environmental phases (i.e. liquid-liquid extraction), such as water and sediment to derive

59 bioaccumulation and bioavailability. Unlike direct measurements, passive samplers only sample

60 the truly dissolved or bioavailable fraction present in the water. ${ }^{8}$ Chemicals sorbed to particles

61 or colloids in the water column are not directly bioavailable (i.e., for passive uptake) and are

62 difficult to separate from the truly dissolved and bioavailable chemicals, such as PAHs. ${ }^{12}$ Thus,

63 when water is sampled for PAHs using conventional methods, the dissolved concentrations are

64 often overestimated due to the inclusion of PAHs associated with colloids. Passive samplers are

65 also a preferred method for measuring PAHs for their ease of sampling, lower detection limits in

66 the field, and minimization of contaminated blanks. ${ }^{12,13}$ Conventional methods of water analysis

67 take samples at a discrete point in time, representing the concentration only at that time, while 
68 the time averaged concentration determined from passive sampling is a more appropriate

69 reflection of the longer-term exposure in the environment. Passive samplers can often be an

70 inexpensive and reliable option compared to conventional methods. ${ }^{12}$

71 Polyethylene samplers (PEs) are passive samplers that have been proven effective at

72 assessing environmental concentrations of organic pollutants. ${ }^{6,7,14}$ Though passive samplers are

73 an excellent option for assessing dissolved PAH concentrations, their performance has not been

74 tested under the harsh conditions of the Arctic environment. Little is currently known how

75 passive samplers accumulate alkylated PAHs, which could be the majority of compounds

76 released during an oil spill. In this study, we (i) determined the $K_{\mathrm{PEw}}$ values of a wide range of

77 alkylated and parent PAHs; (ii) investigated the effect of varying salinities and temperatures on

78 equilibration and partitioning, simulating Arctic conditions; (iii) performed a mock oil spill in the

79 laboratory to evaluate their effectiveness; and (iv) deployed passive samplers in Narragansett

80 Bay, Rhode Island, USA in December 2012 to assess their usefulness in the field.

\section{MATERIALS \& METHODS}

\section{PAHs}

84 Forty-one native PAHs that are commonly present in oil were identified and used to

85 prepare a laboratory standard curve ranging from lower molecular weight components (e.g.,

86 naphthalene) to compounds of higher moleculear weight (e.g., chrysene and benzo(a)pyrene)

87 (Table S1). These standards were prepared by from individual PAHs purchased from certified

88 laboratories (Table S2). Twenty-five of these were alkylated PAHs, as they are commonly found

89 in oil, however there is little research available for these compounds. Additionally, three

90 deuterated PAHs (naphthalene- $\mathrm{d}_{8}$, pyrene- $\mathrm{d}_{10}$, benzo[a]pyrene- $\mathrm{d}_{12}$ ) were utilized as Performance

91 Reference Compounds (PRCs). 


\section{PE samplers}

$94 \quad$ For all experiments, $25 \mu \mathrm{m}$ thick PE, manufactured by a commercial sheeting company

95 (Carlisle Plastics, Inc., Minneapolis, MN, USA), was purchased from a local hardware store.

96 Passive samplers were pre-cleaned in dichloromethane (DCM) twice prior to use. The passive

97 samplers were enriched with PRCs with methods modified from Booij et al (2002) (see SI). ${ }^{15}$

98 For the laboratory portion of the study, PEs were cut into small pieces with a mass of

99 approximately $0.09 \mathrm{mg}\left(\mathrm{ca} .1 \mathrm{~cm}^{2}\right)$. Once samplers were retrieved from the various experiments, 100 they were extracted in DCM and hexane $(1: 1 \mathrm{v} / \mathrm{v})$, with internal surrogates added at the time of

101 extraction. The extracts were then concentrated under a flow of nitrogen gas. Injection standard

102 (external standard) was added prior to analysis with gas chromatography/mass spectrometry

103 (GC/MS) (Agilent, Santa Clara, CA, USA) (see Supporting Information). To validate the

104 GC/MS analysis, a National Institute of Standards and Technology (NIST) PAH standard 2260a

105 was used to calibrate the in-house PAH standard curve (see Supporting Information).

106

107 Polyethylene-water partition coefficients, $\boldsymbol{K}_{\mathbf{P E w}}$

108 Experimental equilibrium partition coefficients were determined in the laboratory for

109 various PAHs (Table S3). In climate controlled rooms, tests were performed to cover the range

110 of temperatures and salinities commonly found in the marine environment, especially conditions

111 present in the Arctic environment and the brine present within ice (see SI and Table S3). ${ }^{16}$ Water

112 samples were prepared at various salinities (245, 100 and $35 \mathrm{psu})$ by using pure water (18.2 $\mathrm{M} \Omega$

$113 \mathrm{~cm}^{-1}$ Milli-Q ${ }^{\circledR}$ filtered water) and Instant Ocean ${ }^{\circledR}$ or Sigma-Aldrich salt mixture, which both

114 mimic the composition of natural seawater. PEs were prepared in triplicate along with a blank 
115 and placed in $1 \mathrm{~L}$ pre-cleaned amber jars filled with water of the various salinities. The six

116 replicate samples were then spiked with a mixture of the 41 oil components in nonane. To

117 facilitate faster equilibrium times, flasks with PEs were stirred to mimic a very turbulent

118 situation in the natural environment. After spiking with PAH mixture (approximately 10 to 90

119 ng depending on the PAH (Table S1)), each replicate was stirred for approximately 24 hours

120 prior to adding the PE sampler. Experiments were run for various time periods to determine if

121 equilibrium was reached (Table S4).

122 The concentrations of the PAHs in the passive samplers (Table S5) and the water were

123 determined and the $K_{\mathrm{PEw}}$ calculated for each compound in each experiment. Experimentally

124 derived $K_{\mathrm{PEw}}$ were compared to $K_{\mathrm{PEw}}$ found in the literature and corrected for changes in

125 temperature and salinity encountered in all experiments using the van't Hoff and Setschenow

126 correction, respectively. ${ }^{17}$

128 Mock oil spill experiment

129 For the mock oil spill experiment, Statfjord crude oil was employed, the composition of

130 which had been previously studied. ${ }^{18,19}$ The water soluble fraction (WSF) of the oil was

131 prepared utilizing filtered natural seawater (Narragansett Bay) by the methods established by the

132 Chemical Response to Oil Spills: Ecological Effects Research Forum (CROSERF) proceedings

133 (see SI). ${ }^{18,19}$ To prevent biological alteration of the WSF, sodium azide was added to the sea

134 water to act as a biocide. The PE samplers were then exposed to the oil WSF at a temperature of

$1355^{\circ} \mathrm{C}$ in an environmental chamber and allowed to reach equilibrium for four weeks. The flasks

136 with PE samplers were stirred on stir plates to facilitate faster equilibrium times. The passive

137 samplers were removed from the water and the PAH concentrations in both PE and water were 
138 determined. The experimentally derived $K_{\mathrm{PEw}}\left(2^{\circ} \mathrm{C}\right.$ at $\left.0 \mathrm{psu}\right)$ were adjusted for the effects of

139 salinity and used to calculate the freely dissolved PAH concentration of the oil WSF and

140 compared to the liquid-liquid extraction results. In a follow-up experiment, triplicate dissolved

141 organic carbon (DOC) samples were collected weekly over 3 weeks. They were filtered

142 (Millipore type RA, $1.2 \mathrm{um}$ ), acidified to $\mathrm{pH} 2$ and refrigerated until analysis on a Shimadzu

143 TOC-V CPH total organic carbon analyzer.

145 Sampling of Narragansett Bay Water for PAHs

PE samplers were field tested in December 2012 over 3 weeks in a tank in the Aquarium

148 Building at the University of Rhode Island's Graduate School of Oceanography (URI-GSO).

149 Tanks were fed Narragansett Bay water pumped through an intake pipe originating under the

150 URI-GSO dock and passed through a sand filter to reduce particles. An in-tank chiller

151 maintained water temperature at $9{ }^{\circ} \mathrm{C}$ in the tank (outside temperature was $12-13{ }^{\circ} \mathrm{C}$ ). The tank

152 measured $1.2 \mathrm{~m}$ Dia $\times 0.6 \mathrm{~m}$ deep with a water level maintained at $0.3 \mathrm{~m}$. The water was pumped

153 into the tank at a rate of $2.4 \mathrm{~L} / \mathrm{min}$. The tank was sampled for DOC daily at the same time each

154 day to track changes over the tidal cycle.

155 Polyethylene samplers measuring ca. $0.1 \mathrm{~m}$ x $0.40 \mathrm{~m}$ x $51 \mu \mathrm{m}$ (ca. $2 \mathrm{~g}$ each) were

156 prepared as a single batch by first cleaning (24 hours in acetone and hexane each) and then

157 impregnating with performance reference compounds, as above. The samplers were each strung

158 on a stainless steel wire and wrapped individually in muffled aluminum foil until deployed. PE

159 samplers were suspended in the water on ropes in 3 groups of 3. One group of PEs was collected

160 at one week intervals for 3 weeks, rewrapped in the aluminum foil and stored in a freezer $(-20$

$\left.161{ }^{\circ} \mathrm{C}\right)$ until analyzed. 
163 through a glass fiber filter (Watman GF/F) and then through tandem polyurethane foam (PUF)

164 plugs. ${ }^{14,20,21}$ This was completed once to per day at the same time each day to track changes in

165 PAH concentrations throughout the tidal cycle. Filters and PUFs were changed weekly in 166 conjunction with collection of the PE strips and stored at $-20^{\circ} \mathrm{C}$ until analyzed. PUF plugs and 167 PE samplers were then analyzed for PAHs (see SI).

168

169

\section{RESULTS \& DISCUSSION}

The experimental $\log K_{\mathrm{PEw}}$ results determined at $20^{\circ} \mathrm{C}$ at 0 psu were plotted against the PAHs' octanol-water partition coefficient ( $\left.K_{\mathrm{ow}}\right)$ (Figure 1, Table S3). As expected, the experimentally determined $\log K_{\mathrm{PEw}}$ values increased with increasing molecular weight and $\log$ $K_{\mathrm{ow}}$, except for acenaphthylene $\left(\log K_{\mathrm{PEw}}=3.17 ; \log K_{\mathrm{ow}}=4.2\right)$. Above $\log K_{\mathrm{ow}}$ of 5.5, measured $K_{\mathrm{PEw}}$ values of PAHs often exceeded their respective $\log K_{\mathrm{ow}}$ values. In general, measured values were within a factor of two (average $71 \%$ ) of $\log K_{\mathrm{ow}}$ values (Table S3).

Exceptions were several alkylated PAHs that were greater than 2-times below their respective $K_{\text {ow }}$ values (e.g., 2-isopropylnaphthalene, 9-ethylfluorene, 2-methylfluorene, and 1,2-

dimethyldibenzothiophene), while the few compounds greater than 2-times above $K_{\text {ow }}$ were mostly higher molecular weight parent PAHs (2,6-diisopropylnaphthalene, 2,4,7-

trimethyldibenzothiophene, benzo(b)fluoranthene, benzo(h)fluoranthene and benzo[a]pyrene).

In the case of the alkylated PAHs, appropriate $K_{\mathrm{ow}}$ literature values were difficult to find; calculations had at times to rely on relationships developed for parent PAHs (e.g., Ma et al., $2010)^{22}$. The deuterated PAHs used as PRCs (naphthalene- $\mathrm{d}_{8}$, pyrene- $\mathrm{d}_{10}$, benzo[a]pyrene- $\mathrm{d}_{12}$ ), 
185 showed good agreement with the non-deuterated PAHs, indicating equilibrium had been reached 186 in the $20{ }^{\circ} \mathrm{C}$ at 0 psu experiments (Table S3).

187 To further validate the experimental $\log K_{\mathrm{PEw}}$ values determined in this study, they were 188 compared to other published results (Table S6). The greatest difference between the published 189 results and the results reached in this study was evident for naphthalene, where other 190 publications determined an average $\log K_{\mathrm{PEw}}$ of 2.8, 3 and 3.23 and this study $\log K_{\mathrm{PEw}}$ of 3.7. 191 The remainder of values determined in this study compared well with previous results, varying 192 only 0.1 to $0.2 \log$ units for most compounds. For some of the HMW PAHs, there was a large 193 spread in the $\log K_{\mathrm{PEw}}$, with the results from this study within the published range. $K_{\mathrm{PEw}}$ agreed 194 best with results from Smedes et al. $(2009)^{23}$. Fernandez et al. (2009) ${ }^{24}$ included four alkylated 195 PAHs, three of which were similar to ones incorporated in this study, specifically 2196 methylphenanthrene (1-methylphenanthrene in this study), 3,6-dimethylphenanthrene, and 2197 methylanthracene (9-methylanthracene in this study). $\log K_{\mathrm{PEw}}$ values derived from the two 198 studies showed excellent agreement with 4.7 and 4.92 for methylphenanthrene, 5.2 and 5.36 for 199 3,6-dimethylphenanthrene, and 5.0 and 4.92 for methylanthracene, respectively. Choi et al. 200 (2013) included a suite of alkylated PAHs in their study, 12 of which were similar to those in this 201 study. ${ }^{25}$ The best agreement between the $K_{\mathrm{PEw}} \mathrm{s}$ in both studies was for 9-methylanthracene, 202 with only $0.12 \log$ units difference, 2-methylphenanthrene (1-methylphenanthrene in this study), 203 with $0.25 \log$ units difference and 1-methylphenanthrene and 2-methylanthracene (9-

204 methylanthracene in this study), both $0.27 \log$ units difference. The largest difference $(0.58 \log$ 205 units) between the alkylated $K_{\mathrm{PEw}}$ of these studies was 6-methylchrysene (1-methylchrysene in 206 this study). The remainder of the alkylated $K_{\mathrm{PEw}}$ values were separated by 0.3 to $0.42 \log$ units. 
The good agreement between parent and alkylated $K_{\text {PEw }}$ values from this and other studies

208 corroborates the $\log K_{\text {PEw }}$ values determined in this study.

A recent review article combined the $\log K_{\mathrm{PEw}}$ values (at $20{ }^{\circ} \mathrm{C}$ and $0 \mathrm{psu}$ ) of various

210 PAHs $(\mathrm{n}=65)$ from independent research studies and correlated them against their respective log $211 K_{\text {ow }}$ values ${ }^{26}$ :

$$
\log K_{\mathrm{PEw}}=1.22( \pm 0.046) \log K_{\mathrm{ow}^{-}} 1.22( \pm 0.24)\left(\mathrm{r}^{2}=0.92, \mathrm{SE}=0.27, \mathrm{n}=65\right)
$$

213 with a high $\mathrm{R}^{2}$ of 0.92 and low standard error (SE) of $0.27 .^{26}$ Focusing only on the parent PAHs,

214 including those from this study, and utilizing $\log K_{\text {ow }}$ values from ${ }^{22}$, the strong linear agreement 215 remains:

$$
\log K_{\mathrm{PEw}}=1.18( \pm 0.04) \log K_{\text {ow }^{-}} 1.06( \pm 0.20)\left(\mathrm{r}^{2}=0.92, \mathrm{SE}=0.31, \mathrm{n}=83\right)
$$

217 To include the alkylated PAHs studied in this data set, $\log K_{\text {ow }}$ values had to be determined.

218 Building upon the parent $\log K_{\text {ow }}$ values, values were added for each methyl group of the 219 alkylated compounds. ${ }^{27}$ All the PAHs included in this study were then incorporated in the data 220 set, resulting in (Figure 1):

$$
\log K_{\mathrm{PEw}}=1.14( \pm 0.04) \log K_{\mathrm{ow}^{-}} 0.95( \pm 0.21)\left(\mathrm{r}^{2}=0.89, \mathrm{SE}=0.34, \mathrm{n}=109\right)
$$

222 Incorporating all of the data from this study slightly decreases the correlation, with slightly

223 higher scatter. Overall, from both the plot and the regression line, it is clear that the log $K_{\mathrm{PEw}}$

224 values determined in this study are similar to other researchers in the field.

The understudied alkylated PAHs were the particular interest to this study, as they could

226 be important contributors to the toxicity of oil. ${ }^{28,29}$ In a recent atmospheric field study, Khairy

227 and Lohmann (2012) reported that tri and tetra-alkylated PAHs partitioned differently into PEs

228 than predicted based on correlations with parent PAHs. ${ }^{30}$ It was unclear at the time whether this 
229 reflected inherent physico-chemical partitioning, was due to sampling bias or a higher reactivity

230 of the higher alkylated PAHs.

231 In this study, the $\log K_{\mathrm{PEw}}$ of $\mathrm{C}_{1}$-alkylated PAHs increased by an average of $0.38 \log$ units

232 compared to the $\log K_{\mathrm{PEw}}$ of the parent PAH. As the number of alkylated carbons increased, so

233 did the difference from the parent (Table 1). With 2 alkylated carbons, the $\log K_{\text {PEw }}$ values

234 increased by an average of $0.67 \log$ units, while with 4 alkylated carbons the difference grew to

235 an average of $1.57 \log$ units. Overall, this suggests that for each additional alkylated carbon, the

$236 \log K_{\text {PEw }}$ increases by an average of $0.40( \pm 0.20) \log$ units relative to the unsubstituted parent

237 PAH $(\mathrm{n}=25)$. For parent PAHs, the average contribution of each aromatic carbon was $0.33( \pm$

238 0.02) $\log$ units $(\mathrm{n}=20)$. In recent work, Choi et al. (2013) reported the carbon contribution

239 towards $\log K_{\mathrm{PEw}}$ as 0.313 (aromatic) and 0.461 (aliphatic), very similar to the results obtained

240 here. ${ }^{25}$ Our values are also in good agreement with the atom/fragment addition method

241 developed by Meyland and Howard (1995), who reported an increase of $0.49\left(-\mathrm{CH}_{2}\right)$ and 0.55

$242 \log$ units $\left(-\mathrm{CH}_{3}\right)$ for alkylated carbon and 0.29 for aromatic carbon in predicting $\log K_{\text {ow }}$ values. ${ }^{27}$

243 This further supports the similarity of partitioning of nonpolar fragments between octanol and

244 polyethylene, as manifested in roughly similar $\log K_{\mathrm{ow}}$ and $\log K_{\mathrm{PEw}}$ values. $^{26}$

245 We compared how well the estimated atom contribution method was able to explain

246 measured values. The agreement was satisfactory; the atom addition method explained $91 \%$ of

247 the variance in the data, with a slope and intercept not significantly different from 1 and 0 ,

248 respectively:

$249 \quad \log K_{\text {PEw, pred }}=0.95( \pm 0.05) \log K_{\text {PEw,meas }}+0.30( \pm 0.25)\left(r^{2}=0.91, \mathrm{SE}=0.40, \mathrm{n}=41\right)$ 
251 Other approaches have been developed to correlate and predict passive sampler partitioning 252 values that go beyond an atom or fragment contribution approach, most notably the poly253 parameter linear free energy relationships (pp-LFER). These are essential for understanding and 254 predicting the partitioning of (a)polar compounds with complex polymers (those with 255 interactions beyond van-der-Waals interactions). Yet in the case of PE, we note that the vast 256 majority of partitioning data has been reported for apolar or weakly polar molecules. This 257 renders pp-LFER approaches for PE difficult to derive. As PE can only interact via van-der-

258 Waals interactions, we deem the above simple carbon addition model appropriate for the task of 259 predicting $\log K_{\mathrm{PEw}}$ for (unknown) alkylated PAHs.

\section{Equilibration of PAHs in experiments}

262 Initial analysis of all of the experiments revealed $\log K_{\mathrm{PEw}}$ of the lower molecular weight

263 (LMW) PAHs increased with increasing $\log K_{\text {ow }}$, while compounds with $\log K_{\text {ow }}$ values above

264 4.5, depending on the experimental temperature and salinity, tended to level off and not continue

265 to increase as expected (Table S3 \& S7). Since neither DOC nor solubility (Table S8) could

266 explain these results, we hypothesized that the higher MW (HMW) PAHs did not reach

267 equilibrium in these experiments. To verify this, the apparent PE-water distributions $\left(K_{\mathrm{PEw}}\right.$,

268 apparent) of the PRCs and native PAHs were compared (Figure 2). The observed \% equilibrium

269 was determined as:

270

$$
\text { PE-W \% equilibrium }(\mathrm{obs})=10 \frac{\left[\log K_{P E w, a p p a r e n t}(\text { native })-\log K_{P E w, a p p a r e n t}(\text { deuterated })\right]}{2} \times 100
$$

271 Naphthalene was equilibrated in all experiments (as evidenced by similar $\log K_{\mathrm{PEw}}$ values

272 between the native and deuterated compound) regardless of temperature and salinity (Table S3). 
273 Deuterated and native pyrene were in equilibrium for all experiments at 20 and $2{ }^{\circ} \mathrm{C}$, but started

274 to diverge to $0.8 \log$ units $\left(-4{ }^{\circ} \mathrm{C}, 100 \mathrm{psu}\right)$ and $3.1 \log$ units $\left(-15^{\circ} \mathrm{C}, 245 \mathrm{psu}\right)$ under colder and

275 saltier conditions (Figure 2 and S1). Benzo(a)pyrene was in equilibrium at the $20^{\circ} \mathrm{C}$

276 experiments, while it did not reach equilibrium in colder and higher salinity experiments. The

277 difference between native and deuterated benzo(a)pyrene reached more than 4 orders of

278 magnitudes at the coldest experiment. This served as evidence that the HMW PAHs, such as

279 pyrene and benzo(a)pyrene, had not reached equilibrium (Figure 2). Lower temperature

280 experiments were analyzed at time intervals one week apart. Overall, the \% equilibrium of

281 pyrene and benzo(a)pyrene gently increased with increasing length of the experiments, but the

282 increase was not significant. For example, at the $-4{ }^{\circ} \mathrm{C}$ experiment, the $\%$ equilibrium for pyrene

283 increased from 16\% (21 days) via 18\% (28 days) to 19\% (35 days). For benzo(a)pyrene, the

284 increase was from $5.6 \%$ via $6.7 \%$ to $8.4 \%$ after 35 days.

285 Both decreasing temperature and increasing salinity affect water viscosity. Assuming that

286 the equilibration of PAHs was limited by the aqueous boundary layer, increasing the water's

287 viscosity should delay equilibration of PAHs, as they have to diffuse across a thicker layer. The

288 experimental set-up allowed us to observe both the effects of salinity and temperature on

289 kinetics, and assess their relative importance. The effect of temperature is clearly visible in

290 comparing the $+2{ }^{\circ} \mathrm{C}$ and $-4{ }^{\circ} \mathrm{C}$ experiments, both performed at $100 \mathrm{psu}$. The $6{ }^{\circ} \mathrm{C}$ temperature

291 decrease slowed down equilibration of pyrene from $100 \%$ to $40 \%$, and that of benzo(a)pyrene

292 from $11 \%$ to $1 \%$ (SI Figure S1). Increasing salinity (e.g., at $20^{\circ} \mathrm{C}$ from 0 to 35 psu) slowed

293 down partitioning such that benzo(a)pyrene was only $72 \%$ equilibrated at the higher salinity.

294 Likewise, increasing the salinity from 0 to $100 \mathrm{psu}$ at $2{ }^{\circ} \mathrm{C}$ reduced the equilibration of

295 benzo(a)pyrene from $56 \%$ to $11 \%$ (Figure 2). 
We established a simple model to better understand the reasons for the slowed down

297 equilibration of PAHs at lower temperature and increasing salinity. The model is similar to

298 equation (22) in ${ }^{26}$ :

299

$$
\frac{1}{k_{e}}=\frac{1}{K_{P E-w} \times \delta_{P E}} \times \frac{1}{\frac{\delta_{w}}{D_{w}}+\frac{\delta_{P E} \times K_{P E w}}{D_{P E}}}
$$

300 where

$k_{\mathrm{e}}$ is the in situ exchange rate constant (1/day),

$\delta_{\mathrm{PE}}$ and $\delta_{\mathrm{w}}$ are the thicknesses of the $1 / 2$ PE sheet, and the water boundary layer (m), and $D_{\mathrm{PE}}$ and $D_{\mathrm{w}}$ are the PAH's diffusivities in PE and water respectively $\left(\mathrm{m}^{2} / \mathrm{s}\right)$

304 The predicted state of equilibrium was calculated as

$$
\% \text { equilibrium }(\text { pred })=\left(1-\mathrm{e}^{-\mathrm{k}_{\mathrm{e}} t}\right)
$$

$$
\text { with time } \mathrm{t} \text { in days }
$$
necessarily sufficient to prevent diffusive control by an aqueous boundary layer. ${ }^{26} \mathrm{We}$ initially assumed $\delta_{\mathrm{w}}=10 \mu \mathrm{m}\left(\delta_{\mathrm{PE}}\right.$ was $\left.12.8 \mu \mathrm{m}\right)$ as an approximation of the boundary layer thickness in a

311 well stirred experiment (see Lohmann, 2012). ${ }^{26}$ Values of $D_{\mathrm{PE}}$ were taken from ${ }^{26}$ and $K_{\mathrm{PE}}$ from

312 this study. $D_{\mathrm{w}}$ was calculated based on the PAHs' molar volume, $\mathrm{V}_{\mathrm{m}}$, (from Fuller, in $\mathrm{cm}^{3} / \mathrm{mol}^{\text {) }}$

313 and the water's dynamic viscosity $\eta$ (in centipoise) ${ }^{17}$ :

$$
D_{w}=\frac{1.326 \times 10^{-4}}{V_{m}^{0.589} \times \eta^{1.14}}
$$

315 The effect of temperature and salinity on $\eta$ was calculated from equations (22) and (23) by

316 Sharqawy et al. (2010) for all experiments. ${ }^{31}$ 
317 The value of $\delta_{\mathrm{w}}=10 \mu \mathrm{m}$ was a good choice for the experiments conducted at $20{ }^{\circ} \mathrm{C}$ at $0 \mathrm{psu}, 20$

$318{ }^{\circ} \mathrm{C}$ at $35 \mathrm{psu}$ and $2{ }^{\circ} \mathrm{C}$ at $0 \mathrm{psu}$, resulting in $<20 \%$ difference between measured and predicted $\%$

319 equilibrium (Figure 2 \& Table S9). We predicted the water boundary layer thickness would

320 increase as the inverse of increasing dynamic viscosity. The $D_{\mathrm{PE}}$ values were left constant

321 throughout these model scenarios, as their temperature-dependency are currently unknown. The

322 glass transition temperature of polyethylene is around $-125^{\circ} \mathrm{C}^{32}$; this should not affect the $D_{\mathrm{PE}}$

323 values of the PAHs in the temperature range considered here. For our different experimental

324 conditions, we predicted $\delta_{\mathrm{w}}$ to increase from an estimated $10 \mu \mathrm{m}$ at $25^{\circ} \mathrm{C}$ and 0 psu to over 64

$325 \mu \mathrm{m}$ at $-15^{\circ} \mathrm{C}$ and $245 \mathrm{psu}$ (Table S9). Overall, this resulted in a decent agreement between

326 measurements and predictions, particularly for the experiments at $20{ }^{\circ} \mathrm{C}, 2{ }^{\circ} \mathrm{C}$ and $-15^{\circ} \mathrm{C}$,

327 whereas the results obtained from the $-4{ }^{\circ} \mathrm{C}$ experiments differed strongly from the predicted

328 results (Figure 2). At $25^{\circ} \mathrm{C}$ (both 0 and $100 \mathrm{psu}$ ), and $2{ }^{\circ} \mathrm{C}(0 \mathrm{psu})$, model and measurements

329 agreed with $<20 \%$. At $2{ }^{\circ} \mathrm{C}$ aand 100 psu, pyrene was still well predicted, but benzo(a)pyrene

330 was predicted to be $43 \%$ equilibrated, while the experiments yielded $11 \%$. At $-4{ }^{\circ} \mathrm{C}$, the model

331 overpredicted equilibration of benzo(a) pyrene by approximately 10-fold, and 5-fold for pyrene.

332 Fairly good agreement was again observed for the final experiments at $-15^{\circ} \mathrm{C}$ at 245 psu, where

333 the model (over) predicted equilibrium within a factor of 2 (benzo(a)pyrene) and 4 (pyrene) of

334 measured results.

335 These results suggest that changes in aqueous viscosity were the main driver slowing

336 down equilibrations in our experiments. We used equation (9) to assess the sensitivity of PAHs'

337 equilibration towards changes in their diffusivity in polyethylene. At $2{ }^{\circ} \mathrm{C}$ and below, the PAH's

338 diffusivity in polyethylene needed to decrease by $10^{3}$ to $10^{4}$ fold to significantly reduce

339 equilibration (i.e., outcompete limitation by $\delta_{\mathrm{w}}$ ). This suggests that the delay in equilibrating 
340 PAHs in our experiments was entirely driven by changes in the water's viscosity, which in turn

341 affects both the PAHs' aqueous diffusivity and the thickness of the water boundary layer. The

342 PAH's diffusivity in the PE almost certainly decreased in the experiments (though it is unknown

343 by how much), but it was most likely not the rate-limiting step. We thus predict that PE

344 deployments in cold, saline water will have to deal with much increased equilibration times, and

345 that these are dictated by the properties of the water, much more so than by the PE properties

346 themselves. Lastly, we note that our experiments were stirred constantly, likely achieving fluid

347 movements well above those found in the oceans, suggesting that our equilibration times are

348 faster than can be observed in the field.

350 Effects of Salinity and temperature on Equilibrium Partition coefficients

351 Initially, we had performed these equilibration experiments to assess the effects of

352 temperature and salinity on equilibrium partition coefficients. Yet as detailed above, our results

353 highlighted the effect of water properties and severely impeded equilibrium in our experiments.

354 The corrections necessary to obtain equilibrium partition coefficients rendered any influences of 355 salinity and temperature difficult to tease out correctly.,

356 More work is needed to confirm whether there is an effect of size on $K_{\mathrm{s}}$ values, as

357 postulated by Ni andYalkowski (2003) ${ }^{33}$, but not observed by Jonker and Muijs (2010). ${ }^{34}$

358 Similarly, it is unclear whether $K_{\mathrm{PEw}}$ values always increase with colder temperatures, as reported

359 by Adams et al. (2007). At least Booij et al. (2003) observed a decrease in $K_{\text {PEw }}$ at lower

360 temperatures for HMW PAHs.

362 Mock Oil Spill Experiment 
After 4 weeks of stirring, the PEs had approached equilibrium (94\% for d-pyrene, 75\%

364 for d-benzo(a)pyrene); no further correction was performed. The WSF for Statfjord crude oil was

365 composed mainly of LMW compounds, such as phenolic compounds, naphthalenes and

366 methylated-naphthalenes, which were similar to reports from previous studies (Table S10). ${ }^{19}$

367 Overall, 36 of the 41 compounds investigated in this study were detected. Naphthalene, methyl-

368 naphthalenes and biphenyl were present in concentrations in the single to tens of $\mu \mathrm{g} / \mathrm{L}$ range.

369 Phenanthrene, methylphenanthrene and fluorene were just below $1 \mu \mathrm{g} / \mathrm{L}$. Very few HMW

370 compounds ( $>200 \mathrm{~g} / \mathrm{mol}$ ) were present in significant concentrations in the WSF of the Statfjord

371 crude oil, confirming previous results (Table S10). ${ }^{19}$ In contrast to other WSF studies, PAH

372 concentrations in our study were not above their subcooled-liquid solubilities in seawater at 5

$373{ }^{\circ} \mathrm{C} \cdot{ }^{35}$

$374 \quad$ Overall, there was good agreement for total PAH concentrations between the two

375 methods. Liquid-liquid extraction yielded $85 \mu \mathrm{g} / \mathrm{L}$ of total PAHs, while PE-based concentrations

376 were $66 \mu \mathrm{g} / \mathrm{L}$. The difference was mostly due to naphthalene results between the two

377 approaches. A closer look at the results revealed an increasing underestimation of passive

378 sampler results with increasing MW of the PAHs (Figure 3; Figure S2). We used filtered

379 seawater, in which DOC was present at $5 \mathrm{mg} / \mathrm{L}$ in the experiments. The partitioning of PAHs to

380 DOC is defined as:

$$
K_{D O C w}=\frac{C_{D O C}}{C_{w}}
$$

where $K_{\mathrm{DOCw}}$ is the equilibrium partitioning constant for PAHs between DOC and water,

383 and $\mathrm{C}_{\mathrm{DOC}}$ is the DOC-bound PAH concentration. We corrected for this third phase effect by 
384 assuming average partitioning of PAHs to DOC $\left(\log K_{\mathrm{DOC}}=1.18 \log K_{\mathrm{ow}^{-}} 1.56\right){ }^{36}$ according to 385 equation (11)

$$
C_{w, \text { corr }}=\frac{C_{w, a p p}}{1+[D O C] K_{D O C w}}
$$

387 in which $[\mathrm{DOC}]$ is in $\mathrm{kg} / \mathrm{L}$, and

$388 \mathrm{C}_{\mathrm{w}, \text { corr }}$ is the DOC-corrected apparent dissolved PAH concentration $\left(\mathrm{C}_{\mathrm{w}, \mathrm{app}}\right)$.

389 For PAHs with a $\log K_{\text {ow }} \leq 5$, both conventional sampling and PE sampling agreed mostly within 390 a factor of 2 (Figure SI 4). For almost all PAHs with a $\log K_{\mathrm{ow}}>5$ (or MW > 200), PE-based 391 results accounted for less than $50 \%$ of liquid-liquid results. While the DOC correction improved 392 the comparison, it was not sufficient to align results for PAHs with higher MW (SI Figure S2). 393 Results in Figure 3 could imply that the estuarine DOC in our seawater displayed a 394 significant higher affinity for PAHs than the mostly freshwater DOCs included in Burkhard's 395 (2000) review. $^{36}$ A similar conclusion was previously reached by Friedman et al. (2011) who 396 reported that polychlorinated biphenyls (PCBs) in the New Bedford Harbor estuary sorbed $5-20$ 397 times stronger to DOC than predicted. ${ }^{37}$ We included results for the DOC-correction of apparent 398 dissolved PAH concentrations from liquid-liquid extraction assuming that DOC sorbed PAHs 5 399 times stronger than predicted by Burkhard ${ }^{36}$, resulting in better agreement between higher MW 400 PAHs from both methods.

401 Overall there was good agreement between the PE samplers and the (DOC-corrected) 402 extracted water concentrations for the most abundant PAHs (Figure 3), mostly within a factor of 403 2. Our experiments highlighted once more the challenge of having other phases, such as DOC 404 present, which greatly exaggerate apparent dissolved concentrations from liquid-liquid 405 extractions. 


\section{Winter deployment in Narragansett Bay water, RI (USA)}

PE field deployments were carried out under quiescent water flow conditions in a tank

409 with flowing seawater to be able to easily sample the water on a daily basis. Unfortunately, this

410 resulted in much reduced sampling rates $\left(\mathrm{R}_{\mathrm{s}}\right)$ compared to previous deployments in Narragansett

411 Bay (Table S11). The $\mathrm{R}_{\mathrm{s}}$ was determined by evaluating the loss rate of the PRCs. Based on loss

412 of $\mathrm{d}_{12}$-pyrene, $\mathrm{R}_{\mathrm{s}}$ ranged from $3-7 \mathrm{~L} /$ day, while they were around $20 \mathrm{~L} /$ day (for pyrene) in

413 previous field deployments in Narragansett Bay. ${ }^{14}$ These low sampling rates effectively

414 prevented us from observing a significant loss of $d_{12}$-benzo(a)pyrene. The predicted loss of

415 benzo(a)pyrene based on a sampling rate of $3-7$ L/day is only around $1 \%$ after 3 weeks, or

416 much smaller than our analytical uncertainty.

417 Results from active sampling implied that apparently dissolved concentrations increased 418 after the first sampling week but remained fairly constant in weeks 2 and 3 (Table S12). Typical

419 concentrations were at or below $1 \mathrm{ng} / \mathrm{L}$ for fluorene, phenanthrene, and methyl-pyrene, $2 \mathrm{ng} / \mathrm{L}$

420 for fluoranthrene and around $6 \mathrm{ng} / \mathrm{L}$ for pyrene (Figure 4), in line with previous results for $421 \quad$ Narragansett Bay water. ${ }^{14}$

422 Truly dissolved PAH concentrations calculated from PE-deployments decreased over 423 time, with increasing certainties of results (Table S13). For the three week deployments, we 424 deduced concentrations of below $1 \mathrm{ng} / \mathrm{L}$ for fluorene, phenanthrene and methyl-pyrene, $2.5 \mathrm{ng} / \mathrm{L}$ 425 for fluoranthrene and $8.6 \mathrm{ng} / \mathrm{L}$ for pyrene. For these 5 representative PAHs, the agreement 426 between active and passive sampling increased from a 30-fold difference (week 1) to 1.4 times 427 (week 2) to within a factor of 1.1. Clearly, deployment times of 2 weeks or more were needed 428 under these quiescent flow conditions to arrive at satisfactory results for the passive samplers. 
429 Within a 3-week deployment window, though, very good agreement was observed between both 430 approaches.

\section{Implications}

433 Our results imply that PE samplers can be used to detect both the parent PAHs, as

434 observed in previous studies, but also a wide range of alkylated PAHs. $K_{\mathrm{PEw}}$ for unknown 435 alkylated PAHs can be approximated by adding $0.40( \pm 0.24) \log$ units per alkylated carbon to

436 the $\log K_{\mathrm{PEw}}$ of the parent PAH. Our experiments were aimed at verifying the use of passive 437 samplers in ice brine, but our results suggest that equilibration in brines below $0{ }^{\circ} \mathrm{C}$ is extremely

438 slow. We investigated these results with a diffusion model. The results suggest that the 439 equilibration is limited by a decrease of the kinematic viscosity, rather than changes of the 440 PAHs' diffusivity in the PE itself. This in turn implies that it will probably affect all passive

441 samplers and most compounds of interest. In open ocean deployments, a decrease of the 442 kinematic viscosity will also lead to a marked slowing down of equilibrations. Including PRCs in 443 PE samplers prior to deployments proved essential for our laboratory work to determine the lack 444 of equilibration, and will be equally important to correct for non-equilibrium under field 445 conditions. The pre-loading of PRCs, as reported by Booij et al. (2002) works well in that regard.

$446{ }^{15}$ Extra matrix and field blanks then serve to determine initial PRC concentrations, which are 447 used to fit a 1-dimensional loss model to the field data. Lastly, we validate the use of PE 448 samplers both for a mock oil spill in the laboratory and under field conditions. Our results 449 suggest that PE samplers are a valuable asset when studying areas without known PAH 450 contamination sources, representing low background concentrations, and can determine the PAH 451 concentrations present in the water column under unique conditions. 


\section{Acknowledgements}

454 This work could not have been accomplished without the help of the following individuals: Eric 455 Morgan, Victoria Dekany, Julia Sullivan, Carey Friedman, Matthew Lambert, Victoria Dekany, 456 Lin Zhang, and Victoria Sacks (all GSO). This project was funded by a grant from NOAA/UNH

457 Coastal Response Research Center. NOAA Grant Number(s): NA04NOS4190063. Project

458 Number: 08-102 'Detecting dissolved PAHs from oil spills using passive samplers in cold water 459 and ice cores'

\section{Supporting Information Available}

462 Additional information on results comparison, figures, and tables were included in the

463 Supporting Information section. This information is available free of charge via the Internet at

464 http://pubs.acs.org/.

465

\section{REFERENCES}

(1) Camilli, R.; Reddy, C. M.; Yoerger, D. R.; Van Mooy, B. A. S.; Jakuba, M. V.; Kinsey, J. C.; McIntyre, C. P.; Sylva, S. P.; Maloney, J. V. Tracking Hydrocarbon Plume Transport and Biodegradation at Deepwater Horizon Science 2010, 330, 201-204.

(2) Reddy, C. M.; Arey, J. S.; Seewald, J. S.; Sylva, S. P.; Lemkau, K. L.; Nelson, R. K.; Carmichael, C. A.; McIntyre, C. P.; Fenwick, J.; Ventura, G. T.; Van Mooy, B. A. S.; Camilli, R. Composition and fate of gas and oil released to the water column during the Deepwater Horizon oil spill Proceedings of the National Academy of Sciences 2011.

(3) Page, D. S.; Boehm, P. D.; Stubblefield, W. A.; Parker, K. R.; Gilfillan, E. S.; Neff, J. M.; Maki, A. W. Hydrocarbon composition and toxicity of sediments following the Exxon Valdez oil spill in Prince William Sound, Alaska, USA Environmental Toxicology and Chemistry 2002, 21, 1438-1450.

(4) Peterson, C. H.; Rice, S. D.; Short, J. W.; Esler, D.; Bodkin, J. L.; Ballachey, B. E.; Irons, D. B. Long-term ecosystem response to the Exxon Valdez oil spill Science 2003, 302, 20822086.

(5) Raineault, L.; Sher, J.: Joe Media Group, Canadian Broadcasting Corporation and Channel 4 International Distribution, 2009., 2009. 
(6) Adams, R. G.; Lohmann, R.; Fernandez, L. A.; Macfarlane, J. K.; Gschwend, P. M. Polyethylene devices: Passive samplers for measuring dissolved hydrophobic organic compounds in aquatic environments. Environ. Sci. Technol. 2007, 41, 1317-1323.

(7) Cornelissen, G.; Pettersen, A.; Broman, D.; Mayer, P.; Breedveld, G. D. Field testing of equilibrium passive samplers to determine freely dissolved native polycyclic aromatic hydrocarbon concentrations Environmental Toxicology and Chemistry 2008, 27, 499-508. (8) Mayer, P.; Tolls, J.; Hermens, L.; Mackay, D. Equilibrium sampling devices Environ. Sci. Technol. 2003, 37, 184A-191A.

(9) Mayer, P.; Reichenberg, F. Can highly hydrophobic organic substances cause aquatic baseline toxicity and can they contribute to mixture toxicity? Environmental Toxicology and Chemistry 2006, 25, 2639-2644.

(10) Morgan, E.; Lohmann, R. Detecting Air-Water and Surface-Deep Water Gradients of PCBs Using Polyethylene Passive Samplers Environ Sci Technol. 2008, 7248-7253.

(11) Xie, W. H.; Shiu, W. Y.; Mackay, D. A review of the effect of salts on the solubility of organic compounds in seawater Mar Environ Res 1997, 44, 429-444.

(12) Namiesnik, J.; Zabiegala, B.; Kot-Wasik, A.; Partyka, M.; Wasik, A. Passive sampling and/or extraction techniques in environmental analysis: a review Anal Bioanl Chem 2005, 381, 279-301.

(13) Lohmann, R.; Booij, K.; Smedes, F.; Vrana, B. Use of passive sampling devices for monitoring and compliance checking of POP concentrations in water Environmental Science and Pollution Research 2012, 19, 1885-1895.

(14) Lohmann, R.; Dapsis, M.; Morgan, E. J.; Dekany, V.; Luey, P. J. Determining air-water exchange, spatial and temporal trends of PAHs in an urban estuary using passive polyethylene samplers Environ Sci Technol 2011, 45, 2655-2662.

(15) Booij, K.; Smedes, F.; van Weerlee, E. M. Spiking of performance reference compounds in low density polyethylene and silicone passive water samplers Chemosphere 2002, 46, 11571161.

(16) Thomas, D. N.; Dieckmann, G. S.; (Editors), Eds. Sea Ice: An Introduction to its Physics, Chemistry, Biology, and Geology; Blackwell Science, Ltd. : Oxford, UK., 2003.

(17) Schwarzenbach, R. P.; Gschwend, P. M.; Imboden, D. M. Environmental Organic Chemistry; 2nd ed.; Wiley-Interscience: New Jersey, 2003.

(18) Aurand, D.; Coelho, G.; (Editors) "Cooperative Aquatic Toxicity Testing of Dispersed Oil and the "Chemical Response to Oil Spills: Ecological Effects Research Forum (CROSERF).”" Ecosystem Management \& Associates, Inc., 2005.

(19) Faksness, L.-G.; P.J. Brandvik; Sydnes, L. K. Composition of the water accommodated fractions as a function of exposure times and temperatures Marine Pollution Bulletin 2008, 56, 1746-1754.

(20) Gioia, R.; Nizzetto, L.; Lohmann, R.; Dachs, J.; Temme, C.; Jones, K. C. Polychlorinated Biphenyls (PCBs) in air and seawater of the Atlantic Ocean: Sources, trends and processes Environmental Science \& Technology 2008, 42, 1416-1422.

(21) Lohmann, R.; Klánová, J.; Kukucka, P.; Yonis, S.; Bollinger, K. PCBs and OCPs on a East-to-West transect: The importance of major currents and net volatilization for PCBs in the Atlantic Ocean Environ Sci Technol 2012, 46, 10471-10479, Doi: 10420.11021/es203459e. (22) Ma, Y. G.; Lei, Y. D.; Xiao, H.; Wania, F.; Wang, W. H. Critical Review and Recommended Values for the Physical-Chemical Property Data of 15 Polycyclic Aromatic Hydrocarbons at $25^{\circ} \mathrm{C}$ Journal of Chemical and Engineering Data 2010, 55, 819-825. 
529 (23) Smedes, F.; Geertsma, R. W.; van der Zande, T.; Booij, K. Polymer-Water Partition

530 Coefficients of Hydrophobic Compounds for Passive Sampling: Application of Cosolvent

531 Models for Validation Environmental Science \& Technology 2009, 43, 7047-7054.

532 (24) Fernandez, L. A.; MacFarlane, J. K.; Tcaciuc, A. P.; Gschwend, P. M. Measurement of

533 Freely Dissolved PAH Concentrations in Sediment Beds Using Passive Sampling with Low-

534 Density Polyethylene Strips Environmental Science \& Technology 2009, 43, 1430-1436.

535 (25) Choi, Y.; Cho, Y. M.; Luthy, R. G. Polyethylene-Water Partitioning Coefficients for

536 Parent- and Alkylated-Polycyclic Aromatic Hydrocarbons and Polychlorinated Biphenyls

537 Environ Sci Technol 2013, 47, 6943-6950.

538 (26) Lohmann, R. A critical review of low-density polyethylene's partitioning and diffusion 539 coefficients for trace organic contaminants and implications for its use as a passive sampler

540 Environ Sci Technol 2012, 36, 606-618, DOI: 610.1021/es202702y.

541 (27) Meylan, W. M.; Howard, P. H. Atom/fragment contribution method for estimating 542 octanol-water partition coefficients J Pharm Sci. 1995, 84, 83-92.

543 (28) Arp, H. P. H.; Azzolina, N. A.; Cornelissen, G.; Hawthorne, S. B. Predicting Pore Water 544 EPA-34 PAH Concentrations and Toxicity in Pyrogenic-Impacted Sediments Using Pyrene 545 Content Environmental Science \& Technology 2011, 45, 5139-5146.

546 (29) Fallahtafti, S.; Rantanen, T.; Brown, R. S.; Snieckus, V.; Hodson, P. V. Toxicity of 547 hydroxylated alkyl-phenanthrenes to the early life stages of Japanese medaka (Oryzias latipes)

548 Aquat. Toxicol. 2012, 106, 56-64.

549 (30) Khairy, M. A.; Lohmann, R. Field Validation of Polyethylene Passive Air Samplers for 550 Parent and Alkylated PAHs in Alexandria, Egypt Environ. Sci. Technol. 2012, 46, 3990-3998.

551 (31) Sharqawy, M. H.; Lienhard V, J. H.; Zubair, S. M. Thermophysical properties of

552 seawater: a review of existing correlations and data Desaliniation and Water Treatment 2010,

553 16, 354-380.

554 (32) Ehrenstein, G. W. Polymeric Materials: Structure, Properties, Applications; Hanser

555 Publishers: Munich, 2001.

556 (33) Ni, N.; Yalkowsky, S. H. Prediction of Setschenow constants Int. J. Pharm. 2003, 254, 557 167-172.

558 (34) Jonker, M. T. O.; Muijs, B. Using solid phase micro extraction to determine salting-out 559 (Setschenow) constants for hydrophobic organic chemicals Chemosphere 2010, 80, 223-227.

560 (35) Redman, A. D.; Mcgrath, J. A.; Stubblefield, W. A.; Maki, A. W.; DiToro, D. M.

561 Quantifying the concentration of crude oil microdroplets in oil-water preparations

562 Environmental Toxicology and Chemistry 2012, 31, 1814-1822.

563 (36) Burkhard, L. P. Estimating dissolved organic carbon partition coefficients for nonionic 564 organic chemicals Environmental Science \& Technology 2000, 34, 4663-4668.

565 (37) Friedman, C.; Lohmann, R.; Burgess, R. M.; Perron, M.; Cantwell, M. G. Resuspension 566 of PCB-contaminated field sediment: Release to the water column and determination of site567 specific KDOC Environmental Toxicology and Chemistry 2011, 30, 377-384.

568 (38) Booij, K.; Hofmans, H. E.; Fischer, C. V.; Van Weerlee, E. M. Temperature-dependent 569 uptake rates of nonpolar organic compounds by semipermeable membrane devices and low570 density polyethylene membranes Environmental Science \& Technology 2003, 37, 361-366. 
Table 1: $\log K_{\mathrm{PEw}}\left(\mathrm{L} / \mathrm{kg}\right.$ ) of parent and alkylated PAHs (determined at $20{ }^{\circ} \mathrm{C}$ at $0 \mathrm{psu}$ ), number of aromatic and alkylated carbon, calculated individual aromatic and alkyl atom contribution to the log $K_{\text {PEw values }}$

\begin{tabular}{|l|c|c|c|c|c|}
\hline PAHs & Log $\boldsymbol{K}_{\text {PEw, meas }}$ & $\mathbf{N}^{\mathbf{0}} \mathbf{C}_{\text {arom }}$ & $\mathbf{N}^{\mathbf{0}} \mathbf{C}_{\text {alkyl }}$ & $\mathbf{C}_{\text {arom }}$ & $\mathbf{C}_{\text {alkyl }}$ \\
\hline Naphthalene & 3.67 & 10 & & 0.37 & \\
\hline Biphenyl & 3.72 & 10 & & 0.37 & \\
\hline Acenaphthylene & 3.17 & 12 & & 0.33 & \\
\hline Dibenzothiophene & 4.27 & 13 & & 0.33 & \\
\hline Phenanthrene & 4.39 & 14 & & 0.31 & \\
\hline Anthracene & 4.43 & 14 & & 0.32 & \\
\hline Fluoranthene & 5.09 & 16 & & 0.32 & \\
\hline Pyrene & 5.22 & 16 & & 0.33 & \\
\hline Chrysene & 5.91 & 18 & & 0.33 & \\
\hline Benz(a)anthracene & 5.91 & 18 & & 0.33 & \\
\hline Benzo(b)fluoranthene & 6.36 & 18 & & 0.35 & \\
\hline Benzo(h)fluoranthene & 6.56 & 18 & & 0.36 & \\
\hline Benzo[a]pyrene & 6.81 & 20 & & 0.34 & \\
\hline Perylene & 6.71 & 20 & & 0.34 & \\
\hline Indeno(1,2,3-c,d)pyrene & 6.47 & 22 & & 0.29 & \\
\hline Dibenzo(a,h)anthracene & 6.76 & 22 & & 0.31 & \\
\hline Benzo(g,h,i)perylene & 6.37 & 22 & & 0.29 & \\
\hline 2-Methyl naphthalene & 3.66 & 10 & 1 & & -0.01 \\
\hline acenaphthene & 3.74 & 10 & 1 & & 0.07 \\
\hline 4,5-Methylene phenanthrene & 4.70 & 14 & 1 & & 0.31 \\
\hline Fluorene & 3.75 & 12 & 1 & & 0.08 \\
\hline 2-Methyl dibenzothiophene & 4.74 & 13 & 1 & & 0.47 \\
\hline 1-Methyl phenanthrene & 4.92 & 14 & 1 & & 0.53 \\
\hline 9-Methyl anthracene & 4.92 & 14 & 1 & & 0.49 \\
\hline 2-Methyl fluorene & 4.53 & 13 & 1 & & 0.77 \\
\hline 1-Methyl pyrene & 5.74 & 16 & 1 & & 0.51 \\
\hline 1-Methyl chrysene & 6.52 & 18 & 1 & & 0.61 \\
\hline 1,5-Dimethyl naphthalene & 4.17 & 10 & 2 & & 0.25 \\
\hline 3,6-Dimethyl phenanthrene & 5.36 & 14 & 2 & & 0.49 \\
\hline 1,2-Dimethyl dibenzothiophene & 4.93 & 13 & 2 & & 0.33 \\
\hline 7,12-Dimethyl benz(a)anthracene & 6.55 & 18 & 2 & & 0.32 \\
\hline 2,3,5-Trimethyl naphthalene & 4.61 & 10 & 3 & & 0.31 \\
\hline 2-isopropyl naphthalene & 4.32 & 10 & 3 & & 0.22 \\
\hline 9-Ethyl fluorene & 4.33 & 12 & 3 & & 0.29 \\
\hline 1,2,5/1,2,7-Trimethyl phenanthrene & 6.36 & 14 & 3 & & 0.65 \\
\hline 2,4,7-Trimethyl dibenzothiophene & 6.57 & 13 & 3 & & 0.76 \\
\hline 1,4,6,7-Tetramethyl naphthalene & 5.01 & 10 & 4 & & 0.34 \\
\hline 1,2,5,6-Tetramethyl naphthalene & 4.98 & 10 & 4 & & 0.33 \\
\hline 9-n-Propyl fluorene & 6.23 & 12 & 4 & & 0.49 \\
\hline Retene & 14 & 4 & & 0.52 \\
\hline 2,6-Diisopropyl naphthalene & 10 & 6 & & 0.40 \\
\hline
\end{tabular}


Figure 1: $\log K_{\mathrm{PEw}}(\mathrm{L} / \mathrm{kg})$ versus $\log K_{\mathrm{ow}}$ of selected PAHs from the literature ${ }^{6,7,23,24,38}$ and those measured in this study at $20^{\circ} \mathrm{C}, 0$ psu for 28 days.

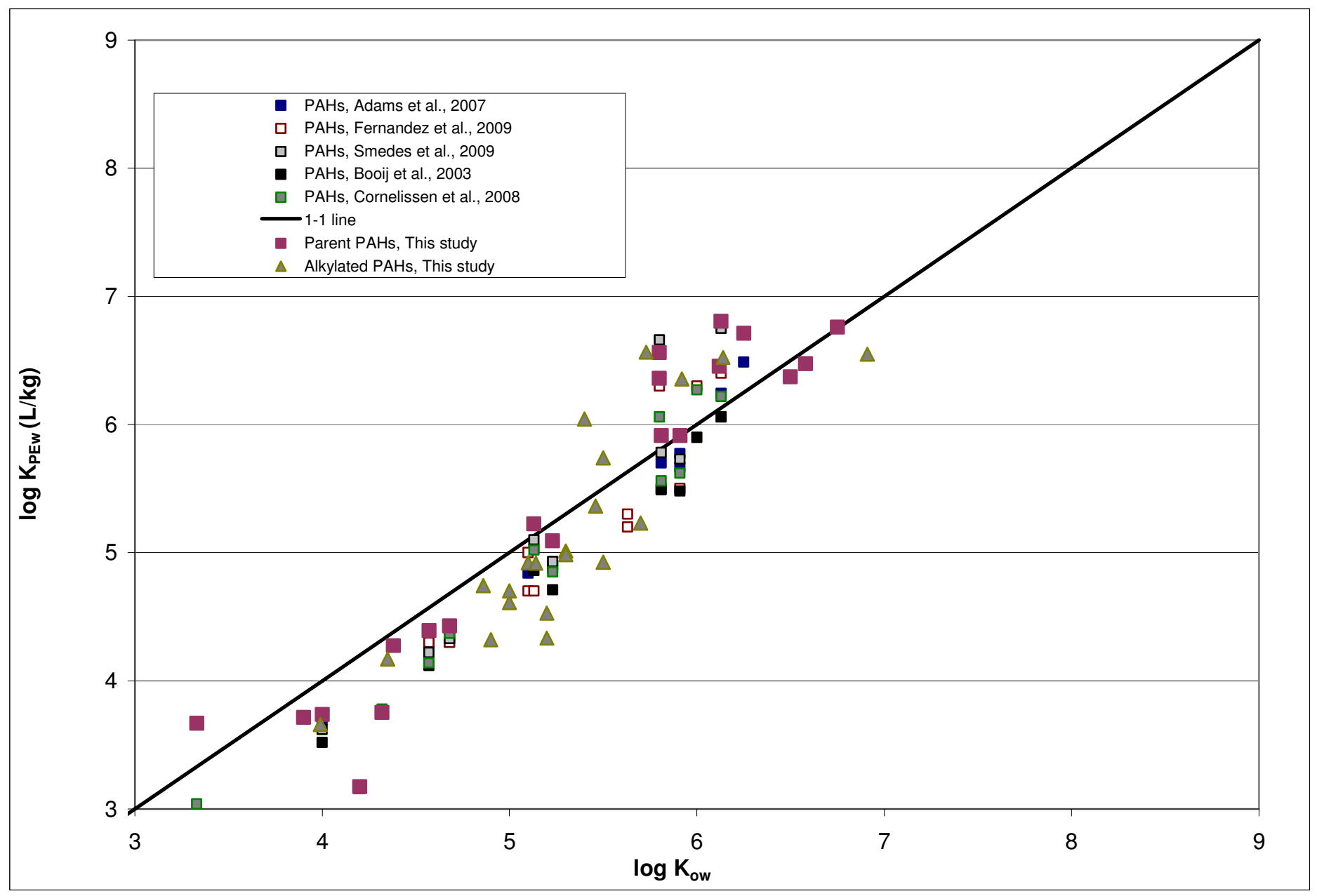


Figure 2: Predicted versus measured (difference between native and deuterated) \% equilibrium for pyrene and benzo(a)pyrene during PE experiments at decreasing temperature and increasing salinity

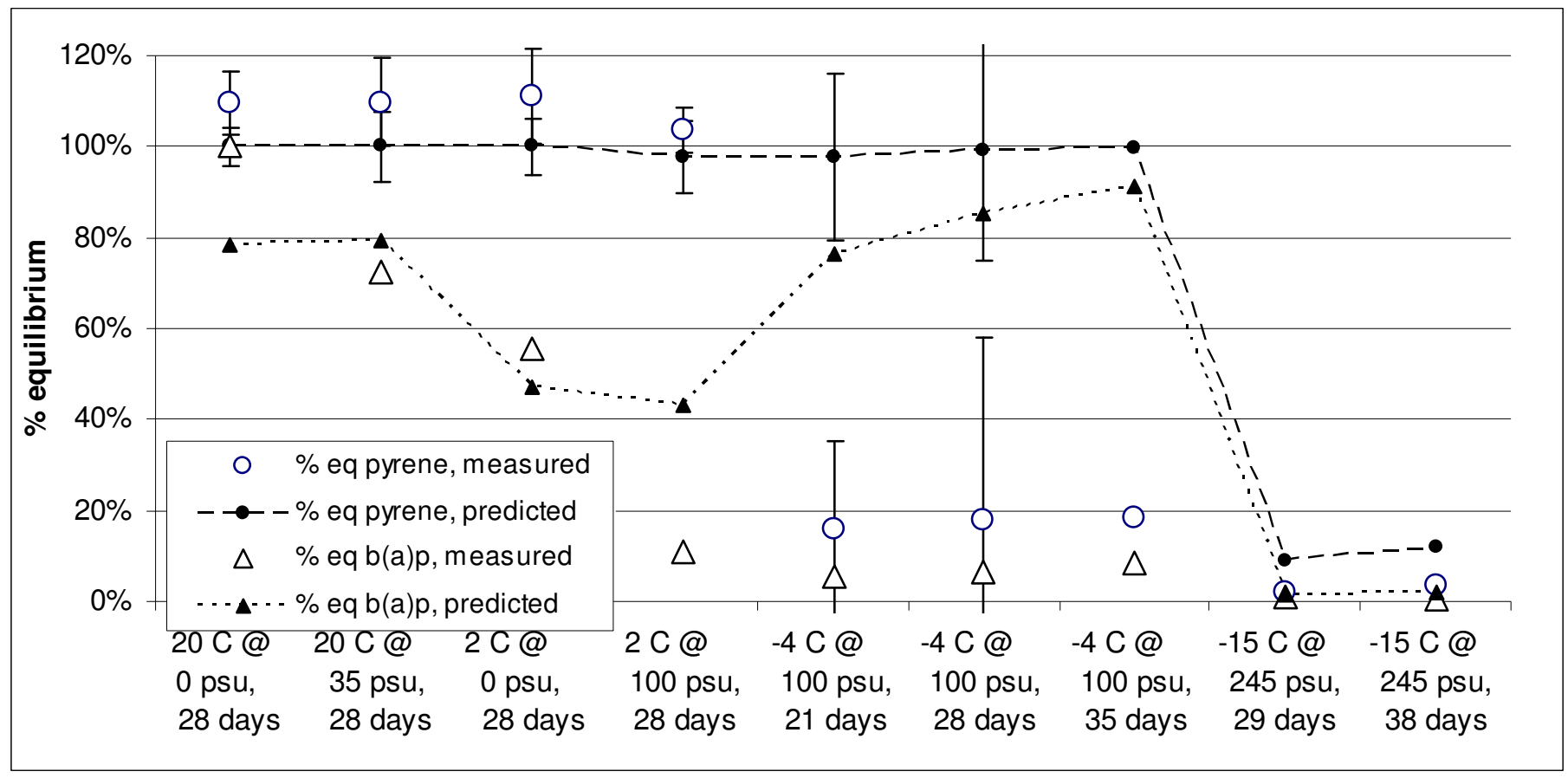


1 Figure 3: Comparison of PAH concentrations from a mock oil spill $\left(5^{\circ} \mathrm{C}, 30 \mathrm{psu}\right)$ : $\mathrm{PE}$ 2 based results versus apparent and DOC-corrected PAH concentrations from liquid-liquid 3 extraction.

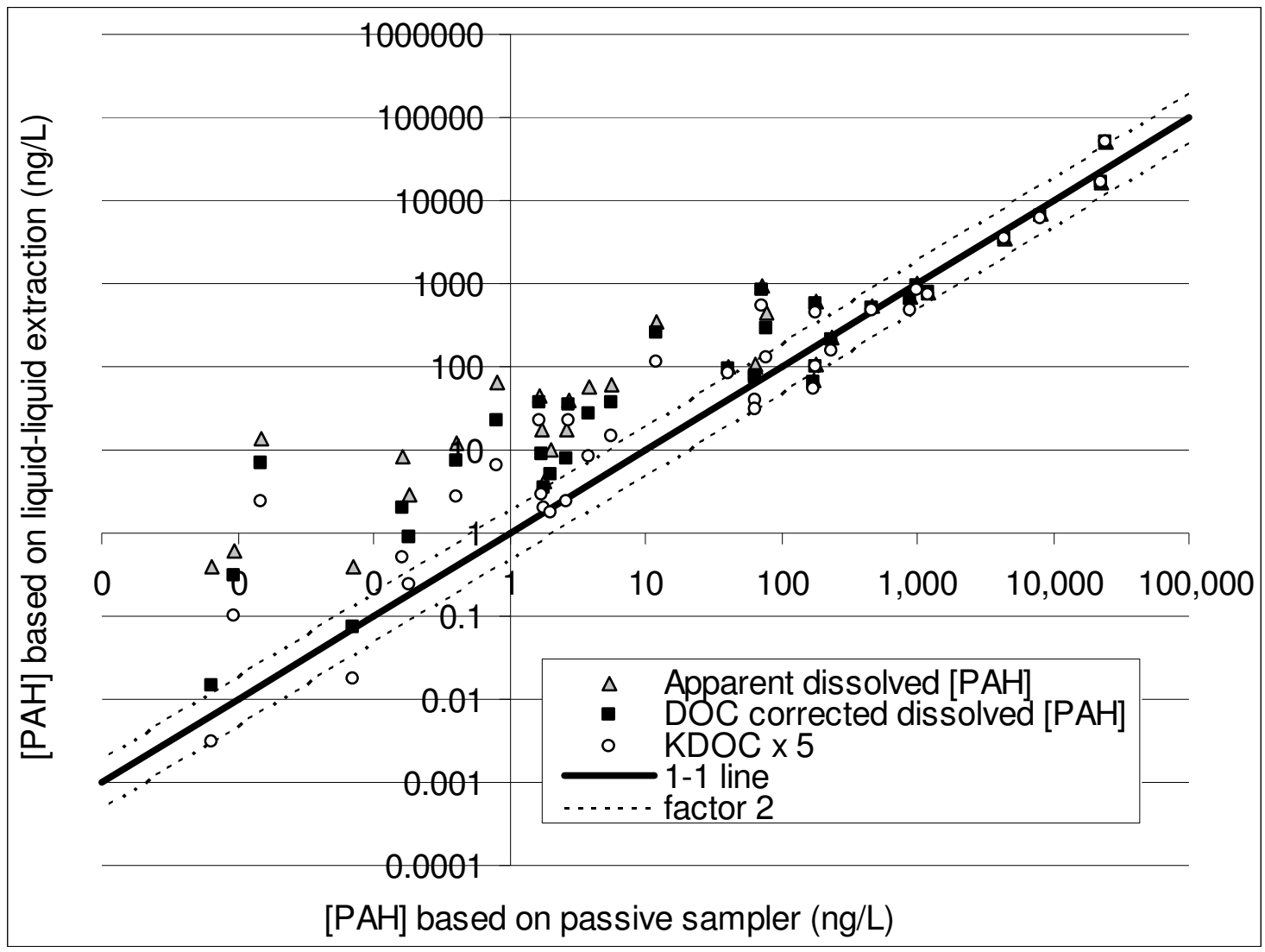


6 Figure 4: Concentrations of selected PAHs (ng/L) in Narragansett Bay water (December 7 2012) from PE-deployments versus weekly active sampling: (a) fluorene; (b) phenanthrene; 8 (c) pyrene; (d) fluoranthene

9
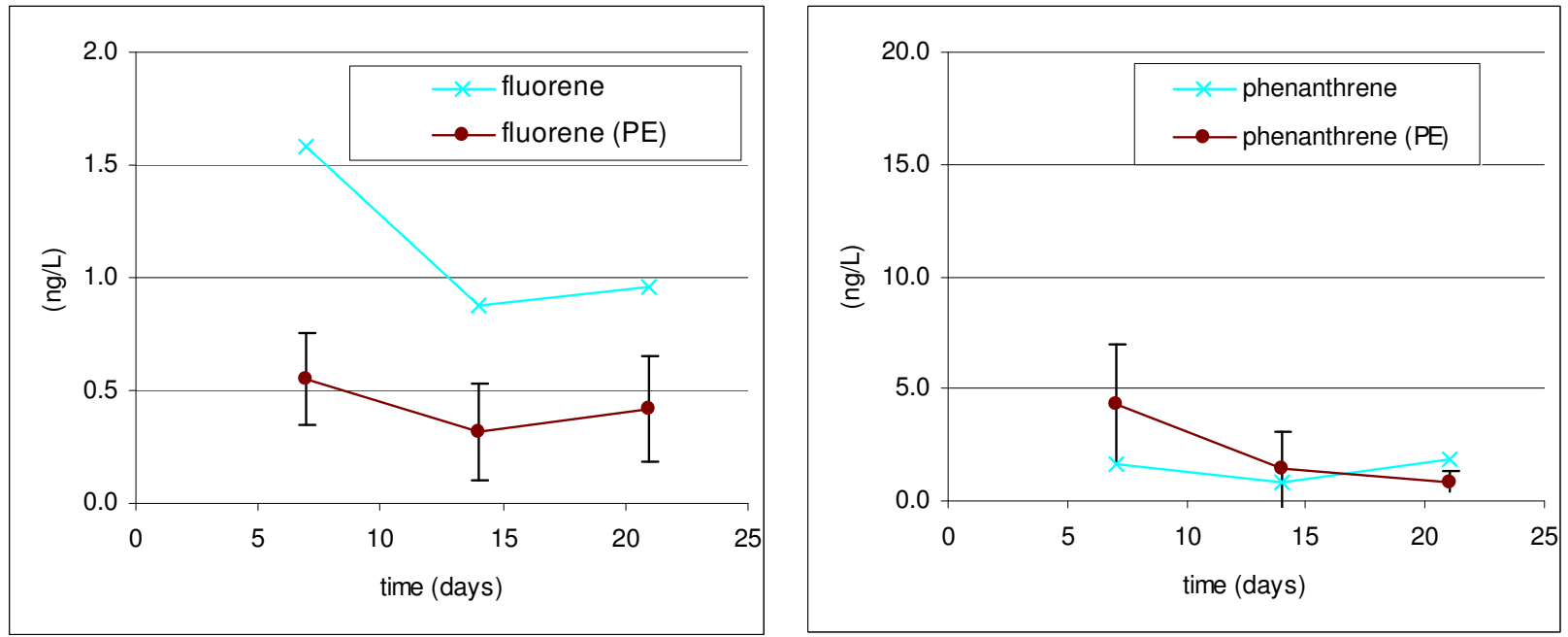

10
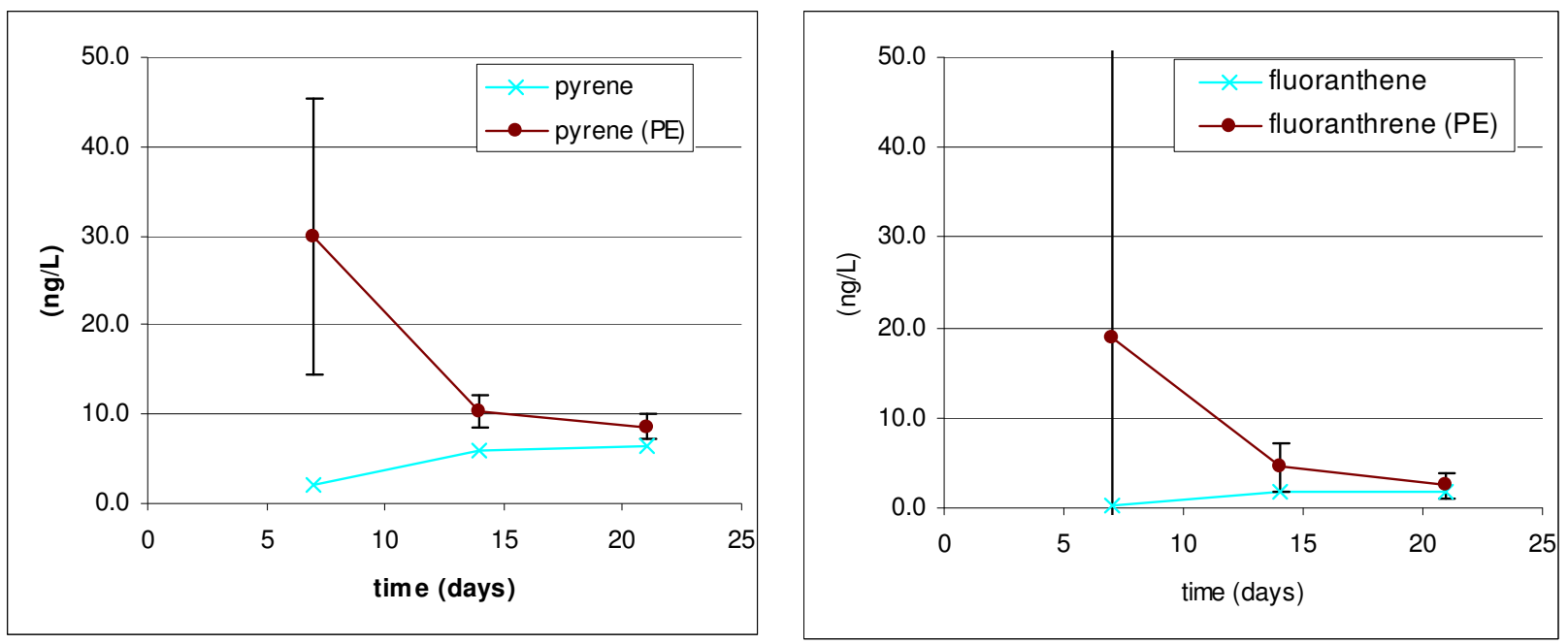

11

12 


\section{$\log \mathrm{K}_{\mathrm{PEw}} \mathrm{S}$ of PAHs at $-15^{\circ} \mathrm{C} \& 245$ psu after 5 weeks of stirring}

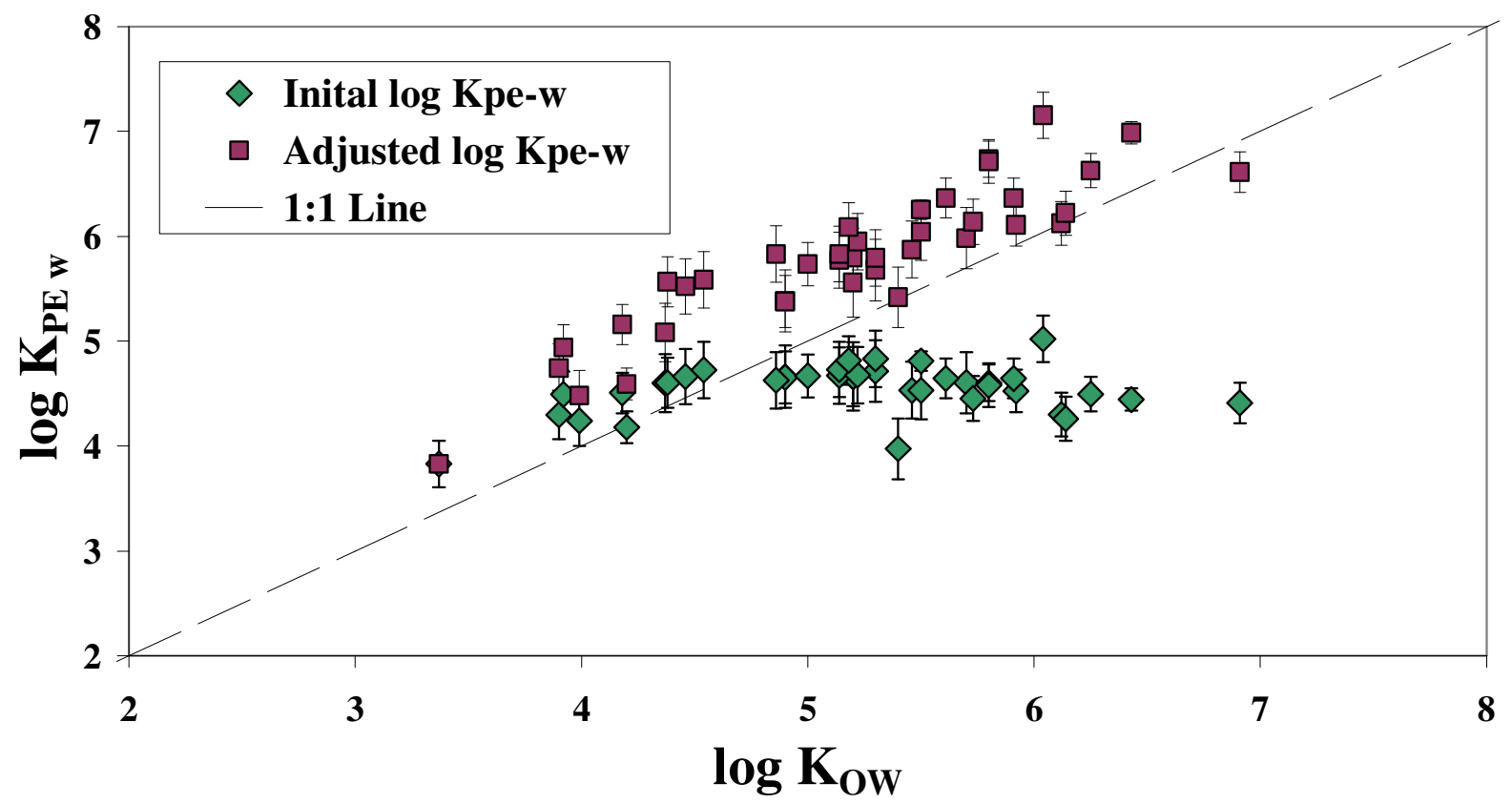

